7. Reprod. Fert. (1971) 24, 417-421

\title{
SOME EFFECTS OF OXYTOCIN IN VITRO ON RAT UTERINE SMOOTH MUSCLE
}

\author{
H. G. REES* \\ Department of Animal Health, Massey University, New Zealand \\ (Received 27th February 1970, revised 23rd September 1970)
}

Brief treatment of experimental subjects with progestagens or oestrogens has been shown to achieve a marked modification of the response to oxytocin (Burnstock, Holman \& Prosser, 1963; Reynolds, 1965). Isolated uterine muscle, when stretched, liberates a substance that slowly increases uterine tone to the point of contracture (Jung, 1966) but with an isometric method the problems of unrecorded stretch do not arise (Schofield, 1954; Csapo, 1954). With these points in mind, two experiments were undertaken to define the effects of oestrogen and progestagens on the response of the myometrium to stimulus with synthetic oxytocin. Both experiments were based on a block-type factorial model (Snedecor, 1956) in which the treatment of each of the three experimental groups was repeated four times.

Thirty-six Sprague-Dawley female rats in the prepubertal stage were bilaterally ovariectomized under ether anaesthesia and kept at $65^{\circ} \mathrm{F}$ on wood shavings in metal cages with never more than six animals to a cage. They were fed on Massey mouse pellets Type 2 (Lawson, 1964).

Subcutaneous injections of oestradiol monobenzoate (B.D.H.), and progesterone (Organon) in 0.1 and $1.0 \mathrm{ml}$ of arachis oil, respectively, were given for assigned pre-treatment periods.

Thirty-six rats (nine for each replication) were randomly allotted to one of the pre-treatment combinations (Rees, 1967) with a pattern of dosing as outlined in Plan 1.

\section{Plan 1}

Group I

$$
\begin{array}{cccccr}
\text { Oestradiol }(\mu \mathrm{g}) & \text { Progesterone }(\mathrm{mg}) & \text { Day 1 } & \text { Day 2 } & \text { Day 3 } & \text { Day 4 } \\
5 & \mathbf{P} & \mathbf{P} & \mathbf{P}+\mathrm{Oe} & \mathbf{P}+\mathrm{Oe}
\end{array}
$$

Group II

$\begin{array}{cccccc}\text { Oestradiol }(\mu \mathrm{g}) & \text { Progesterone }(\mathrm{mg}) & \text { Day 1 } & \text { Day 2 } & \text { Day 3 } & \text { Day 4 } \\ 10 & 1 & \text { P } & \text { P } & \text { P+Oe } & \text { P+Oe }\end{array}$

Group III

$$
\text { Oestradiol }(\mu \mathrm{g})
$$

Progesterone (mg)

$\begin{array}{cccc}\text { Day } 1 & \text { Day } 2 & \text { Day } 3 & \text { Day } 4 \\ \mathbf{P} & \mathbf{P} & \mathbf{P}+\mathrm{Oe} & \mathbf{P}+\mathrm{Oe}\end{array}$

The pattern of dosing in the pre-treatment combinations for each group was repeated four times, different rats being used for each replication.

The animals were killed and a single uterine horn from each rat was used in Exp. 1, the opposite horn from twenty-four rats being used in Exp. 2. The

* Present address : c/o Davey, M.R.c.v.s. and Jones, M.R.c.v.s., 47, Merthyrmawr Road, Bridgend, Glamorgan. 
excised uterine strips (one complete uterine horn) were immersed in a Magnustype organ bath containing Ringer solution (de Jalon, Bayo \& de Jalon, 1945) at room temperature.

The pre-warmed oxytocin, which was in contact with the preparation for $45 \mathrm{sec}$, was administered in doses of $1,2,4$ and $8 \mathrm{mU}$ with a 5-min interval between doses. The preparation was washed for $30 \mathrm{sec}$ before and after the oxytocin had been administered.

Areas on the kymograph tracings corresponding to the four dose levels of oxytocin were outlined by perpendicular lines drawn through the points on the continuous trace at which oxytocin had been administered (Text-fig. 1). Two other perpendicular lines were drawn at a distance equivalent to $90 \mathrm{sec}$ on either side of the administration line, during which the preparation was

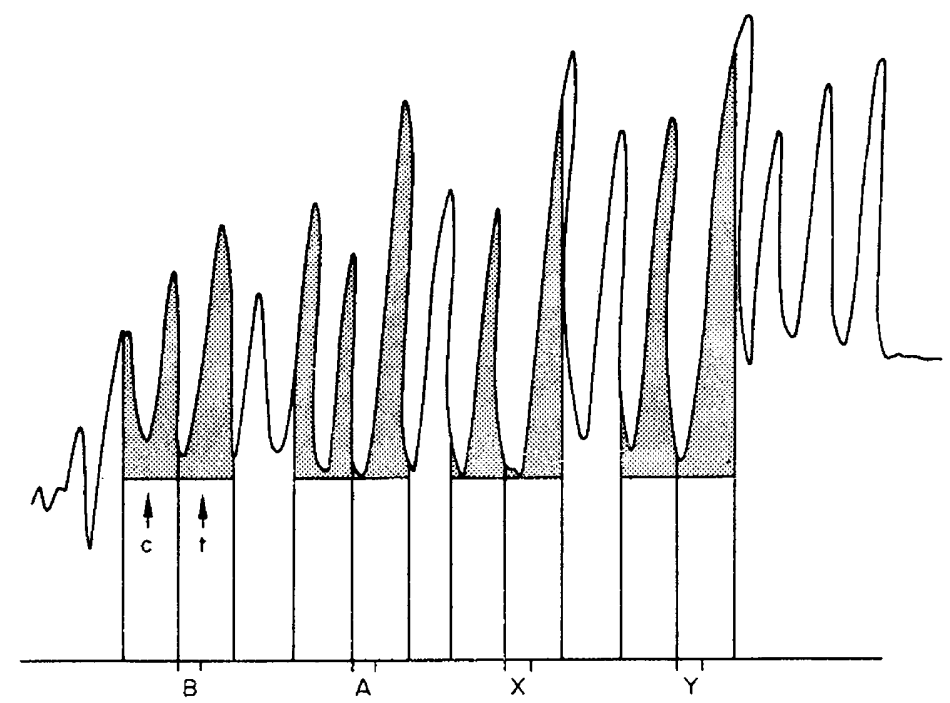

TEXT-FIG. 1. Diagram of tracing from rat uterine strip. This illustrates the method used in taking the area measurements with a planimeter. $c=$ Control area before oxytocin stimulus; $\mathbf{t}=$ treatment area after oxytocin stimulus. $B, A, X, Y=1,2,4$ and $8 \mathrm{mU}$ oxytocin respectively.

oxytocin-free. The base line for these areas was drawn through the two lowest points of the kymograph record. Each individual area was measured twice with the planimeter and only if the measurements differed by less than $0.004 \mathrm{~cm}^{2}$ was the mean of the two readings accepted.

The control readings were subtracted from the contraction readings and the differences were transformed to logarithms after coding to remove negative readings.

The mean square due to differences between contractions was highly significant, $P<0.001$ (Rees, 1967). This effect was examined further by a $t$ test of differences between the four means (see Table 1). The mean response to $8 \mathrm{mU}$ oxytocin was greater than that to $4 \mathrm{mU}(P=0.05)$, which, in turn, was greater than that to $2 \mathrm{mU}(P<0.001)$. 
The mean responses for individual treatment combinations and for each level of oestradiol and progesterone are shown in Table 2. The results of this analysis indicate a significant effect for progesterone treatment $(P<0.05)$ though this was not a simple linear response. The total mean square for the effect of oestradiol was not significant. There was evidence of interaction between the linear responses of the two steroid hormones $(P<0 \cdot 10)$, on the one hand, and interaction between the non-linear responses $(P<0.05)$ on the other. The former effect was due to differences in response to the two extreme doses of oestradiol

TABLE 1

MEAN RESPONSE ACCORDING TO DOSE LEVEL OF OXYTOCIN AND OESTRADIOL PRE-TREATMENT

\begin{tabular}{c|cccc}
\hline \multirow{2}{*}{$\begin{array}{c}\text { Oestradiol level } \\
(\mu g)\end{array}$} & \multicolumn{4}{|c}{ Oxytocin dose level $(m U)$} \\
\cline { 2 - 5 } & 1 & 2 & 4 & 8 \\
\hline 5 & 1.075 & $1 \cdot 181$ & $1 \cdot 137$ & 1.314 \\
10 & $\frac{1.131}{1.119}$ & 1.257 & 1.339 & 1.374 \\
20 & 1.025 & 1.350 & 1.378 \\
\hline All levels & 1.108 & 1.115 & 1.275 & 1.355 \\
\hline
\end{tabular}

Means joined by underlining do not differ significantly from each other but do differ significantly from the values not underlined and from those underlined separately.

TABLE 2

MEAN RESPONSE ACCORDING TO DOSE LEVEL OF PROGESTERONE AND OESTRADIOL

\begin{tabular}{c|cccc}
\hline \multirow{2}{*}{$\begin{array}{c}\text { Oestradiol level } \\
(\mu \mathrm{g})\end{array}$} & \multicolumn{4}{|c}{ Progesterone level $(\mathrm{mg})$} \\
\cline { 2 - 5 } & 1 & 5 & 10 & All levels \\
\hline 5 & 1.303 & 1.086 & $1 \cdot 141$ & $1 \cdot 177$ \\
10 & 1.356 & 1.310 & 1.160 & 1.275 \\
20 & 1.226 & 1.133 & 1.295 & 1.218 \\
\hline All levels & 1.295 & 1.176 & $1 \cdot 199$ \\
\hline
\end{tabular}

in combination with low progesterone as against high progesterone. The latter effect indicates that the response to the most effective dose of oestradiol, the intermediate dose, differed when given with an intermediate dose of progesterone from that when given with either of the other doses of progesterone.

The modifying effect of oestradiol on the response to progesterone was examined by using a $t$ test to detect significant differences between the mean for oestradiol levels within each progesterone level in Table 2. The results of this examination are summarized below:

$$
\mid \begin{array}{l|l|l}
\mathrm{P}_{1} \mathrm{O}_{3} & \mathrm{P}_{2} \mathrm{O}_{1} & \mathrm{P}_{3} \mathrm{O}_{1} \\
\mathrm{P}_{1} \mathrm{O}_{1} & \mathrm{P}_{2} \mathrm{O}_{3} & \mathrm{P}_{3} \mathrm{O}_{2} \\
\mathrm{P}_{1} \mathrm{O}_{2} & \mathrm{P}_{2} \mathrm{O}_{2} & \mathrm{P}_{3} \mathrm{O}_{3}
\end{array}
$$


The symbols $\mathrm{P}$ and $\mathrm{O}$ designate progesterone and oestradiol and the subscripts 1, 2 and 3, the low, intermediate and high doses, respectively. Within each column, the mean responses are in increasing order from top to bottom. Means not joined by the vertical line differ significantly $(P<0.05)$. At the lowest dose of progesterone, which gave greater response than the other two levels of this hormone, the level of oestradiol did not have a significant effect. At the intermediate level of progesterone, the intermediate level of oestradiol offset the depressing effect of increased progesterone, whereas at the high level of progesterone, only the high level of oestradiol offset the depressing effect of the other steroid.

When the interaction between contractions and pre-treatment was partitioned, only the interaction between the pre-treatment level of oestradiol and oxytocin dose was significant, $P<0.05$ (Rees, 1967). The relevant means for this interaction are presented in Table 1 and these have been further examined by a $t$ test.

The overall means show a stepwise increase with oxytocin dose, increases which were significant apart from that between the two lowest doses, but this effect was not uniform between pre-treatment levels of oestrogen. Interaction was confined to the relative position of the two intermediate levels of oxytocin. At all levels of oestradiol, the highest level of oxytocin gave a mean response which was significantly greater than that of the lowest level.

An additional experiment was performed, in which the opposite uterine horn was examined, for six of the nine treatment levels used:

$$
\mathrm{P}_{1} \mathrm{O}_{1} ; \mathrm{P}_{1} \mathrm{O}_{3} ; \mathrm{P}_{2} \mathrm{O}_{2} ; \mathrm{P}_{2} \mathrm{O}_{3} ; \mathrm{P}_{3} \mathrm{O}_{2} ; \mathrm{P}_{3} \mathrm{O}_{3}
$$

The alternate horns were assembled immediately their counterparts, selected at random for the main experiment, had been removed from the organ bath.

Two doses of oxytocin, $1 \mathrm{mU}$ and $4 \mathrm{mU}$, were administered on Day 5, for $3 \mathrm{~min}$, with $10 \mathrm{~min}$ between each dose. The preparation was washed twice before the second oxytocin administration, once at the removal of the $1-\mathrm{mU}$ dose and again within $5 \mathrm{~min}$, allowing a further $5 \mathrm{~min}$ to elapse before the 4-mU dose was given.

The area for the $6 \mathrm{~min}$ immediately before the administration of oxytocin was deducted from the sum of the areas for the two 3-min periods described. The response for the level of oxytocin administered was compared with the responses to these levels for the appropriate pre-treatments in the main experiment and an analysis of variance was carried out for each of the doses of oxytocin used (Rees, 1967). There were no significant differences between the results obtained by two different observers.

It was concluded that differences related to the particular pre-treatment combination that had been used were largely due to the progesterone component. Oestradiol, at appropriate dosage, tended to overcome the depressing effect of increasing doses of progesterone, although this did not appear to be a simple relationship.

The magnitude of the response obtained was clearly dependent on the dose of oxytocin irrespective of the pre-treatment combination that had been used. Even though an interaction between the oxytocin dose and the pre-treatment 
level of oestradiol was observed in these experiments, the overall responses still showed a stepwise increase with increasing doses of oxytocin.

This investigation was carried out at Massey University, New Zealand, in partial fulfilment of the requirements for the M.V.Sc. degree. Thanks are extended to Professor E. D. Fielden and Professor R. A. Munford of Massey University, whose continued guidance and interest made this study possible. Thanks are also due to Organon Laboratories Ltd for providing the steroid hormones used in these experiments.

\section{REFERENGES}

Burn, J. H., Finney, D. J. \& Goodwin, L. G. (1950) Biological standardization, 2nd edn. Oxford University Press, London.

Burnstock, G., Holman, M. E. \& Prosser, G. L. (1963) Electrophysiology of smooth muscle. Physiol. Rev. 43, 482.

Csapo, A. I. (1954) Dependance of isometric tension and isotonic shortening of uterine muscle on temperature and on strength of stimulation. Am. F. Physiol. 177, 348.

Garcia de Jalon, P., Bayo Bayo, J. M. \& Garcia de Jalon, M. (1945) Farmacoter act. 2, 313 (cited by Burn et al., 1950).

Jung, H. (1966) A myometrial substance affecting the uterus. Mem. Soc. Endocr. 14, 253.

LAwson, R. A. S. (1964) A study of some aspects of growth and reproduction in two inbred lines of mice and their crosses. M.Agr.Sc. thesis, Massey University of Manawatu.

REEs, H. G. (1967) Some effects of oxytocin on in vitro preparations of uterine muscle. M.V.Sc. thesis, Massey University.

Reynolds, S. R. M. (1965) Physiology of the uterus, 2nd edn. Hafner, New York.

SCHOFIELD, B. M. (1954) The influence of oestrogen and progesterone on the isometric tension of the uterus in the intact rabbit. Endocrinology, 55, 142.

SNEDECOR, G. W. (1956) Statistical methods, 5th edn. Iowa State University Press, Ames, Iowa. 